\title{
Ginsenosides Extracted from Nanoscale Chinese White Ginseng Enhances Anticancer Effect
}

\author{
Yanxia $\mathrm{Ji}^{1,2}$, Ziyu Rao², Jinlei Cui², Haiying Bao ${ }^{1, *}$, Chunying Chen²,*, \\ Chunying $\mathrm{Shu}^{3}$, and Jian Ru Gong ${ }^{2, *}$ \\ ${ }^{1}$ School of Chinese Medicinal Material, Jilin Agricultural University, Changchun 130118, P. R. China \\ ${ }^{2}$ National Center for Nanoscience and Technology, China, 11 Zhongguancun Beiyitiao, Beijing 100190, P. R. China \\ ${ }^{3}$ Beijing National Laboratory for Molecular Sciences, Beijing 100080, P. R. China
}

\begin{abstract}
Ginsenosides, the major chemical composition of Chinese white ginseng (Panax ginseng C. A. Meyer), can inhibit tumor, enhance body immune function, prevent neurodegeneration. In this paper, for the first time we reported that the amount of ginsenosides in the equivalent extraction of the nanoscale Chinese white ginseng particles (NWGP) was 2.5 times more than that of microscale Chinese white ginseng particles (WGP). And the extractions from NWGP $(1000 \mu \mathrm{g} / \mathrm{ml})$ reached a high tumor inhibition of $64 \%$ exposed to human lung carcinoma cells (A549) and $74 \%$ exposed to human cervical cancer cells (Hela) after $72 \mathrm{~h}$. Our work shows that the nanoscale Chinese WGP greatly improves the bioavailability of ginsenosides.
\end{abstract}

Keywords: Ginsenosides, Nanoscale Chinese White Ginseng, Anticancer, In Vitro.

\section{INTRODUCTION}

Chinese white ginseng (Panax ginseng C. A. Meyer) is one of the precious herbs in traditional Chinese medicine (TCM) as a tonic, prophylactic agent in the whole world, particularly in China, Korea, and Japan. ${ }^{1}$ In the past decade, promising advances were achieved in understanding the chemistry, ${ }^{2}$ pharmacology, ${ }^{3}$ and structure-function relationship of Chinese white ginseng. ${ }^{4}$ Ginsenosides are the main ingredients of Chinese white ginseng and have lots of pharmacological activities, such as anti-tumor, ${ }^{5}$ antioxidation, ${ }^{6}$ immunomodulation. ${ }^{7}$ However, ginsenosides are expensive and not suitable for long-term use. Therefore, it is necessary to improve the utilization of the ginsenosides in the Chinese white ginseng.

Nanomaterials have displayed potential applications ${ }^{8}$ in the fields ranging from drug delivery ${ }^{9}$ to imaging. ${ }^{10}$ There have been some studies on the use of nanotechnology in TCM,11 such as some TCM raw materials were directly crushed into nanometer size by machines, ${ }^{12}$ some active ingredients of TCM materials and nanocarriers composed the drug-nanocarrier systems. ${ }^{13}$ The drug efficacy is improved using the above mentioned methods, ${ }^{14}$ because the nanoparticles have larger specific surface

\footnotetext{
${ }^{*}$ Authors to whom correspondence should be addressed.
}

areas, stronger solvent penetration and thus higher extraction yield. It was reported that the ginseng powders about 8 micrometers was prepared by the ultra-fine grinding processing..$^{15}$ However, to the best of our knowledge, the anti-cancer application of the nanoscale Chinese white ginseng was never reported before.

In this study, we compared the amount and the anticancer property of ginsenosides in the microscale Chinese white ginseng particles (WGP) and the nanoscale Chinese white ginseng particles (NWGP). We found that the amount of ginsenosides in the equivalent extraction of the NWGP samples were more than that in the microscale WGP samples, and the NWGP extractions also had a stronger tumor inhibition effect than that in the microscale WGP extractions due to the facilitation of the larger specific surface area of the NWGP.

\section{EXPERIMENTAL DETAILS}

\subsection{Materials}

Chinese white ginsengs (Panax ginseng C. A. Meyer) were cultivated and identified (by Pro. Bao) in Jilin Agricultural University (Changchun, China). Ginsenosides Rg1, $\mathrm{Re}, \mathrm{Rb} 1$, and $\mathrm{Rd}$ were purchased from National Institutes for Food and Drug Control (Beijing, China). 


\subsection{Preparation and Characterization of WGP}

As a starting material, Chinese white ginseng samples with the size of 100 mesh $(150 \pm 6.6 \mu \mathrm{m})$ was used. $2.89 \mathrm{~g}$ WGP mixed with agate balls with $10,6 \mathrm{~mm}$ $(\Phi 10 \mathrm{~mm}: \Phi 6 \mathrm{~mm}=50: 10)$ of diameter were sealed in a polytetrafluoroethylene installation with agate balls-toWGP weight ratio of 10:1 and rotated at speed of $600 \mathrm{rpm}$. The NWGP was obtained following the three-step procedure for $30 \mathrm{~h}$, clockwise rotation-stillness-anticlockwise rotation with each step kept for $30 \mathrm{~min}$. The milling was performed with Type QM-3SP04 planetary ball bill (China).

The morphologies and sizes of WGP and NWGP were characterized by an S-4800 field emission scanning electron microscopy (SEM, Hitachi, Japan).

\subsection{Ginsenosides Extraction}

\subsubsection{Extraction for FTIR and Anti-Tumor In Vitro Tests

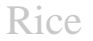

Ultrasound-assisted extraction was performed in an ultrasonic cleaner with the output power of $100 \mathrm{~W}$ and the frequency of $40 \mathrm{kHz}$. $2.00 \mathrm{~g} \mathrm{WGP}$ and NWGP were placed into two $100 \mathrm{ml}$ conical flasks respectively, and $60 \mathrm{ml}$ of $70 \%(\mathrm{v} / \mathrm{v})$ ethanol-water were added. The mixtures were filtrated, and the extractions were transferred into a $200 \mathrm{ml}$ volumetric flask after $30 \mathrm{~min}$ in an ultrasonic water bath, then removed the solvent using an evaporator. The samples used for Fourier transform infrared spectrometer (PerKin-Elmer) and anti-tumor in vitro tests were dried by freeze-drying.

\subsubsection{HPLC Sample Preparation}

$0.50 \mathrm{~g}$ WGP and $0.50 \mathrm{~g}$ NWGP samples were extracted with $70 \%$ ethanol-water in a Soxhlet extractor for $8 \mathrm{~h}$ at $85^{\circ} \mathrm{C}$, respectively. The extracts were concentrated in vacuum, transferred into a $10 \mathrm{ml}$ volumetric flask, and then diluted to the desired volume with methanol (HPLC grade, Duksan Pure Chemical Co., Ltd.). Two samples were prepared in parallel to test the variations, and all experiments were performed at least 3 times. The solutions were stored at $4{ }^{\circ} \mathrm{C}$ until HPLC analysis.

\subsection{Chromatographic Conditions}

Chromatographic analysis was performed using a Waters 600E HPLC instrument (Milford, MA) with a quaternary pump, an automatic injector, and a UV detector (Model 2487). Chromatographic separation was carried out on an Atlantis dC18 column ( $5 \mu \mathrm{m}, 4.6 \times 150 \mathrm{~mm}$, Waters Crop.) at a column temperature of $30{ }^{\circ} \mathrm{C}$. The detection wavelength was set to $203 \mathrm{~nm}$. The mobile phase consisted of acetonitrile (A) and water (B) using a gradient elution of
22-30\% A at 0-20 min, 30-33\% A at 20-25 min, 33-37\% $\mathrm{A}$ at $25-35 \mathrm{~min}, 37-50 \% \mathrm{~A}$ at $35-40 \mathrm{~min}, 50-22 \% \mathrm{~A}$ at 40-50 $\mathrm{min}$. The flow rate was kept at $1 \mathrm{ml} / \mathrm{min}$, and the injected sample volume was set at $10 \mu \mathrm{l}$.

\subsection{Experiments of Anti-Tumor In Vitro}

\subsubsection{Cell Culture}

Cells were cultured in Dulbecco's modified Eagle's medium (DMEM) supplemented with L-alanyl-Lglutamine $(2 \mathrm{mM})$, antibiotics $(100 \mathrm{U} / \mathrm{ml}$, penicillinstreptomycin), and $10 \%$ fetal bovine serum (FBS). Cells were maintained in a humidified atmosphere at $37{ }^{\circ} \mathrm{C}$ and $5 \% \mathrm{CO}_{2}$.

\subsubsection{Anti-Tumor In Vitro}

We employed the classic CCK-8 viability assay to evaluate and compare the anticancer effect of WGP and NWGP. The human lung carcinoma epithelial-like cell lines (A549) were plated in the 96 -well plates $\left(3 \times 10^{3}\right.$ cells per well $)$ and incubated for $24 \mathrm{~h}$, and human cervical cancer cell lines (Hela) were plated in the 96 -well plates $\left(5 \times 10^{3}\right.$ cells per well) and incubated for $24 \mathrm{~h}$. WGP and NWGP were introduced separately to cells with different test concentrations $(50,100,200,500,1000 \mu \mathrm{g} / \mathrm{ml})$ in the culture medium. Cells cultured in the medium without ginseng were taken as the control. After 24, 48, and $72 \mathrm{~h}$ incubation, the cells were washed with phosphate buffer solution (PBS) three times. $100 \mu \mathrm{l}$ DMEM containing CCK-8 (10\%, v/v, Dojindo Molecular Technologies, Inc.)were added to each well. After $2 \mathrm{~h}$ incubation at $37{ }^{\circ} \mathrm{C}$, the absorbance at $450 \mathrm{~nm}$ of each well was measured using a microplate reader (TECAN Infinite M200, Austria).

\subsection{Statistical Analysis}

All data are expressed as the mean with the standard deviation (mean $\pm \mathrm{SD}$ ). A one-way analysis of variance (ANOVA) was employed to the results from studies on cell viability. The unpaired Student's t test was applied to identify significant differences between the groups treated with WGP and NWGP. $P<0.05$ is considered to be a significant difference. ${ }^{*}$ denotes a statistical significance $\left({ }^{*}<0.05\right.$ and $\left.^{* *}<0.01\right)$ of NWGP versus WGP.

\section{RESULTS AND DISCUSSION}

In this study, NWGP was prepared by dry milling WGP (100 mesh, $150 \pm 6.6 \mu \mathrm{m})$ in a planetary ball bill as described in the experimental section. We found that the nanoscale WGP have a lighter color observed with the naked eyes and feel smoother in hands compared 
to the microscale WGP. The SEM image (Fig. 1(a)) displayed that the WGP samples had a large tangled agglomeration, crude surfaces, and the size ranging from 3 to $8 \mu \mathrm{m}$. In contrast, Figure 1(b)-(c) showed that the NWGP had the loose fine particles with irregular shapes and smaller sizes in the range of 500-600 $\mathrm{nm}$. Obviously, the NWGP had larger specific surface areas than the microsized WGP.

In our experiment, ginsenosides extractions from WGP and NWGP were collected and analyzed by FTIR spectrometer. The infrared spectra (red) in Figure 2 showed the functional groups of ginsenosides in NWGP. For instance, the strongest peak at $3402 \mathrm{~cm}^{-1}$ was belonged to the stretching vibration of $\mathrm{O}-\mathrm{H}$ groups, the peak at $2930 \mathrm{~cm}^{-1}$ was assigned as the stretching vibration of $\mathrm{C}-\mathrm{H}$ in methyl and methylene groups, ${ }^{16}$ the peak of symmetric and asymmetric COO- stretching vibration was focused on $1640 \mathrm{~cm}^{-1}$ and $1406 \mathrm{~cm}^{-1},{ }^{17}$ respectively. $1051 \mathrm{~cm}^{-1}$ was assigned as the bending vibration of $\mathrm{C}-\mathrm{C}-\mathrm{O}$ or $\mathrm{C}_{-} \mathrm{C}_{-} \mathrm{OH}$ in starch. ${ }^{18}$ The infrared spectra characteristics of ginsenosides in WGP were similar to those in NWGP, although the peak intensity of ginsenosides in the WGP/samples and the NWGP samples was different. Therefore, the chemical structures of ginsenosides didn't change from microscale WGP to NWGP.
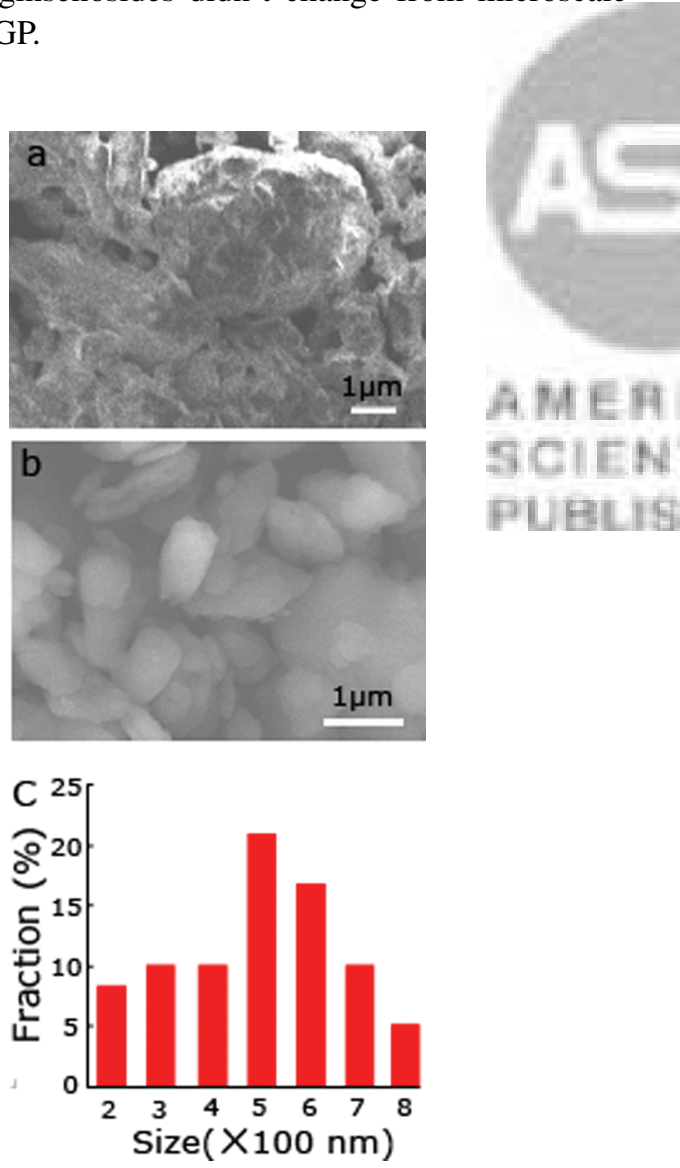

Fig. 1. SEM images of Chinese white ginseng samples in microsize (a) and nanosize (b), (c) A histogram of the nanosized WGP by measuring the dimensional sizes.

J. Nanosci. Nanotechnol. 12, 6163-6167, 2012

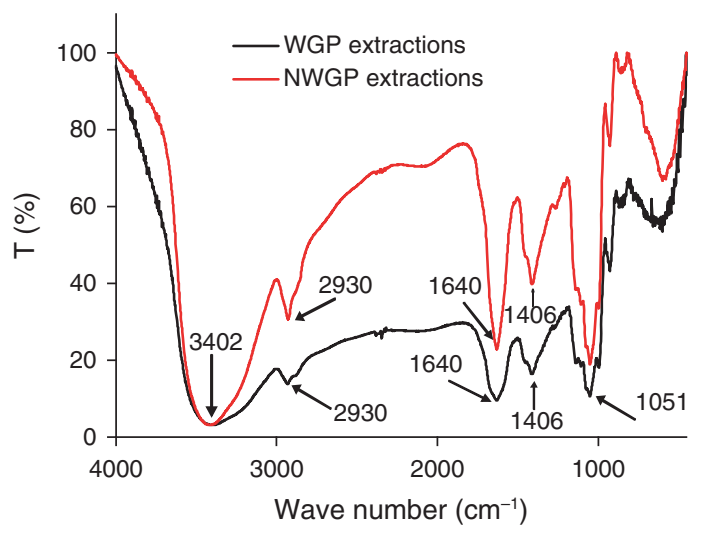

Fig. 2. FTIR spectra of WGP extractions (black) and NWGP extractions (red) with $\mathrm{KBr}$ disc in the ranges from 4000 to $400 \mathrm{~cm}^{-1}$.

It is believed that the major bioactive compounds in Chinese white ginseng are ginsenosides. ${ }^{19}$ The typical HPLC-UV chromatograms of ginsenosides extracts from WGP and NWGP were shown in Figures 3(b) and (c), respectively. Based on the component analysis and the comparison between individual and mixed ginsenoside, the structures were the same due to the existence of the same retention time, and Table I indicated that there were great difference in the content percentage of ginsenosides from WGP and NWGP samples. Ginsenosides Rb1, Rd, Rg1, and $\mathrm{Re}$ were four major ginsenosides in white ginseng, accounting for more than $70 \%$ of the total ginsenoside contents. ${ }^{20}$ Due to the distinct variation in contents of ginsenosides in the different Chinese white ginseng samples, four methanol stock solutions of standards $(\operatorname{Rg} 1, \mathrm{Re}$, $\mathrm{Rb} 1, \mathrm{Rd})$ were prepared and diluted with methanol solution to appropriate concentration for the establishment of
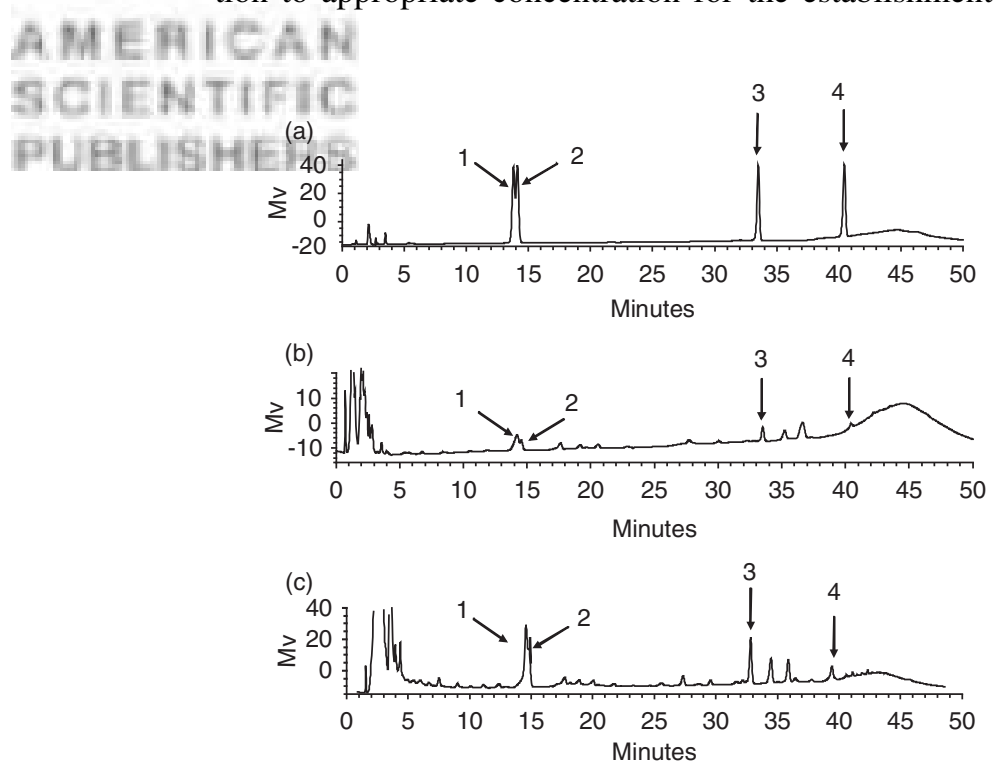

Fig. 3. Typical HPLC-UV chromatograms at $203 \mathrm{~nm}$ of Chinese white ginseng: (a) mixture standards of Chinese white ginseng, (b) WGP, (c) NWGP. Ginsenoside peaks: (1) Rg1, (2) Re, (3) Rb1, (4) Rd. The concentrations of ginsenoside standards were all $0.5 \mathrm{mg} / \mathrm{ml}$. 
Table I. The contents of Rb1 and Rd in WGP and NWGP by the HPLC calibration curve.

\begin{tabular}{|c|c|c|c|c|c|}
\hline \multirow{2}{*}{$\begin{array}{l}\text { Gin } \\
\text { senosid }\end{array}$} & \multirow{2}{*}{$\begin{array}{c}\mathrm{RT} \\
(\mathrm{min})\end{array}$} & \multirow{2}{*}{$\begin{array}{l}\text { Calibration } \\
\text { curve }^{a}\end{array}$} & \multirow{2}{*}{$\begin{array}{l}\text { Correlation } \\
\text { coefficient } \\
\left(\mathrm{r}^{2}\right)\end{array}$} & \multicolumn{2}{|c|}{$\begin{array}{c}\text { Extraction percentage } \\
(\mathrm{mg} / \mathrm{g} \text { dry WG) }\end{array}$} \\
\hline & & & & WGP & NWGP \\
\hline Rg1 & 13.81 & $A=2 \times 10^{6} c-118076$ & 0.9980 & 2.370 & 6.312 \\
\hline $\mathrm{Re}$ & 14.11 & $A=2 \times 10^{6} c-69464$ & 0.9965 & 0.972 & 2.978 \\
\hline $\mathrm{Rb} 1$ & 33.51 & $A=2 \times 10^{6} c-113139$ & 0.9997 & 1.500 & 3.868 \\
\hline $\mathrm{Rd}$ & 40.44 & $A=2 \times 10^{6} c-82154$ & 0.9992 & 0.919 & 2.638 \\
\hline
\end{tabular}

${ }^{a} A=$ Peak Area, $c=$ Concentrations $(\mu \mathrm{g} / \mathrm{ml})$.

calibration curves. Five concentrations $(0.02-0.5 \mathrm{mg} / \mathrm{ml})$ of four ginsenosides solutions were injected in triplicate, and then the calibration curves were constructed by plotting the peak areas against the concentration of each analyte. Table I showed that the content percentage of four ginsenosides in NWGP was 2.5 times more than that in WGP according to the HPLC-UV chromatograms. Though the baseline shifted occasionally, there was little influence on the results. So the extraction percentage of ginsenosides from NWGP was greatly increased compared with that from WGP.

The cell viability was investigated to estimate the anticancer property of Chinese white ginseng samples quantitatively by Cell Counting Kit-8 (CCK-8) assay. ${ }^{21}$ Briefly, a certain volume of solution containing tetrazolium salt (available in the CCK-8 Kit from Dojindo Laboratories, Japan) was used. The mitochondria's ability to reduce a tetrazolium salt to a formazan dye was used to assess mitochondrial dehydrogenase activity. Traditionally, we always used MTT or MTS ${ }^{22}$ test to evaluate the cytotoxicity. However, the CCK- 8 solution was more convenient and the absorbance of the CCK- 8 assay solution was higher than that of MTT or MTS. Therefore, we chose the CCK-8 solution to test the cell viability. The tumor inhibition or cytotoxicity was the inverse of cell viability (\% of control). The cell viability was expressed as the percentage of $\left(O D_{\text {test }}-O D_{\text {blank }}\right) /\left(O D_{\text {control }}-O D_{\text {blank }}\right)$, where $O D_{\text {test }}$ was the optical density of the cells exposed to ginseng samples, $O D_{\text {control }}$ was the optical density of the control sample and $O D_{\text {blank }}$ was the optical density of the wells

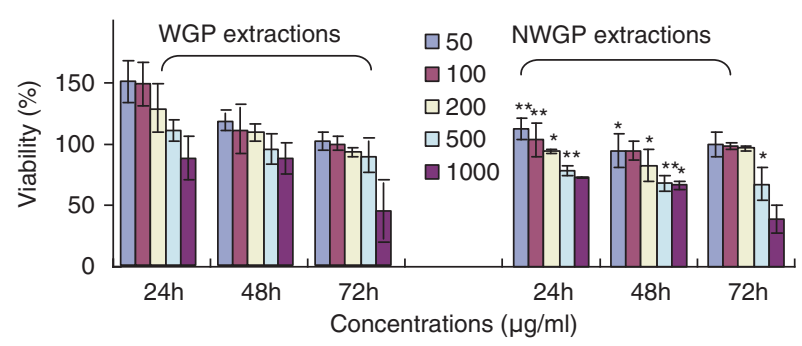

Fig. 4. The viability of A549 cells after exposed to the WGP extractions and the NWGP extractions $(50,100,200,500,1000 \mu \mathrm{g} / \mathrm{ml})$ for $24 \mathrm{~h}$, $48 \mathrm{~h}, 72 \mathrm{~h}$.

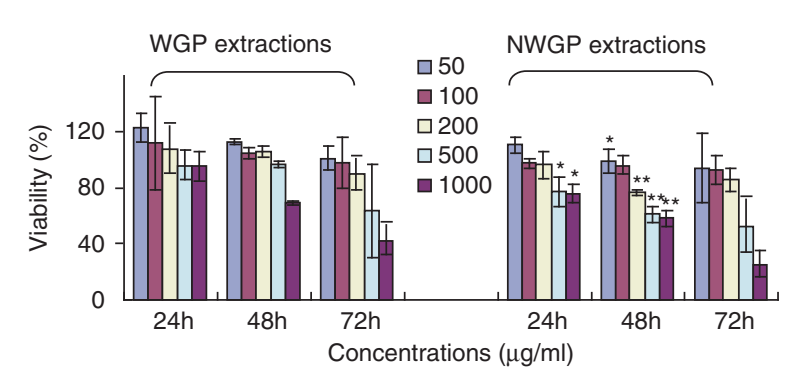

Fig. 5. The viability of Hela cells after exposed to the WGP extractions and the NWGP extractions $(50,100,200,500,1000 \mu \mathrm{g} / \mathrm{ml})$ for $24 \mathrm{~h}$, $48 \mathrm{~h}, 72 \mathrm{~h}$.

without A549 cells or Hela cells. Figure 4 indicated a dose-dependent and time-dependent cytotoxicity in terms of CCK-8 reduction in A549 cells. At higher concentrations and longer time, the viability loss was observed in the cells treated with ginsenosides both in WGP extractions and NWGP extractions. The influence of WGP extractions on the tumor inhibition of A549 cells was tiny in $24 \mathrm{~h}$. Even at the highest concentration of $1000 \mu \mathrm{g} / \mathrm{ml}$, less than . $15 \%$ of the cell tumor inhibition remained. However, the tumor inhibition of NWGP in A549 cells for $24 \mathrm{~h}, 48 \mathrm{~h}$ at $1000 \mu \mathrm{g} / \mathrm{ml}$, near $30 \%$ and $35 \%$ of the cell inhibition remained. So NWGP extractions enhanced the anti-tumor effects. Similar results were obtained from $72 \mathrm{~h}$ exposure, the highest tumor inhibition up to $62 \%$.

Likewise, Figure 5 displayed a dose-dependent and time-dependent cytotoxicity in terms of CCK-8 reduction in Hela cells. The influence of WGP extractions on the tumor inhibition of Hela cells was also tiny in $24 \mathrm{~h}$. Even at the highest concentration of $1000 \mu \mathrm{g} / \mathrm{ml}$, only $5 \%$ of the cell tumor inhibition remained. However, the tumor inhibition of NWGP in Hela cells for $24 \mathrm{~h}, 48 \mathrm{~h}$ at $1000 \mu \mathrm{g} / \mathrm{ml}$, near $25 \%$ and $40 \%$ of the cell inhibition remained. The highest tumor inhibition up to $74 \%$ at $1000 \mu \mathrm{g} / \mathrm{ml}$ exposure $72 \mathrm{~h}$ in Hela cells. These results collectively indicated that NWGP extractions enhanced the anti-tumor effects to a great extent.

In short, the amount of ginsenosides in the NWGP extractions was more than 2.5 times compared with that in the WGP extractions according to the HPLC-UV chromatograms, and the NWGP extractions enhanced the antitumor effects compared with the WGP extractions in A549 cells and Hela cells, especially exposed to A549 cells in a short time. We proposed that the larger specific surface area of NWGP facilitated the extraction of ginsenosides. That is, the NWGP extractions enhanced the anti-tumor effects due to a higher bioavailability of the ginsenosides in the NWGP compared to that in the microscale WGP.

\section{CONCLUSIONS}

In summary, we successfully prepared nanoscale Chinese white ginseng with $500-600 \mathrm{~nm}$ by dry milling in a 
planetary ball bill, and the amount of ginsenosides in the equivalent extraction of the NWGP was 2.5 times more than that of microscale WGP. Furthermore, the NWGP extractions reached a higher tumor inhibition exposed to A549 cells and Hela cells compared with the WGP extractions. Our work shows that the nanoscale Chinese white ginseng greatly improves the bioavailability of ginsenosides, which are essential for economizing the herb materials and improving officinal value.

Acknowledgment: This work was supported by the National Basic Research Program of China (No. 2011CB933401), the National Natural Science Foundation of China (Nos. 21005023, 91123003), and the special foundation on ginseng industry development of Jilin province (00262).

\section{References and Notes}

1. (a) S. Zhang, R. Chen, H. Wu, and C. Wang, J. Pharmi Biomed. Anal. 41, 57 (2006); (b) T. K. O. O. Yun, Ann. N.Y. Acad. Sci. 889, 157 (1999); (c) K. Choi, Acta. Pharm. Sin. 29, 1109 (2008); (d) Y. Sasaki, K. Komatsu, and S. Nagumo, Bio. Pharmac. Bul." 31, 1806 (2008).

2. N. Fuzzati, J. Chromatogr. B. 812, 119 (2004).

3. (a) C. L. Broadhurst, M. M. Polansky, and R. A. Anderson, J. Agric. Food. Chem. 48, 849 (2000); (b) L. Wang, and W. S. Kisaalita, J. Neurosci. Methods 2, 274 (2010); (c) L. Wang, Q. M. Liu, B. H. Sung, D. S. An, H. G. Lee, S. G. Kim, S. C. Kim, S. T. Lee, and W. T. Im, J. Biotechnol. 2, 125 (2011).

4. (a) S. Shibata, J. Korean Med. Sci. 16, S28 (2001); (b) E. A. Bae, M. J. Han, M. K. Choo, S. Y. Park, and D. H. Kim, Bio. Pharm. Bull. 25, 58 (2002).

5. (a) C. Chen, W. Chiou, and J. Zhang, Acta. Pharmacol. Sin. 29, 1103 (2008); (b) A. B. Fishbein, C. Z. Wang, X. L. Li, S. R. Mehendale, S. Sun, H. H. Aung, and C. S. Yuan, Arch. Pharm. Res. 32, 505 (2009); (c) V. K. W. Wong, S. S. F. Cheung, T. Li, Z. H. Jiang, J. R. Wang, H. Dong, X. Q. Yi, H. Zhou, and L. Liu. J. Cell. Biochem. 111, 899 (2010); (d) D. C. W. Lee, and A. S. Y. Lau, Molecules 16, 2802 (2011).
6. (a) C. Y. O. Chen, J. D. Ribaya-Mercado, D. L. McKay, E. Croom, and J. B. Blumberg, Food Chem. 119, 445 (2010); (b) K. Norajit, K. M. Kim, and G. H. Ryu, J. Food Eng. 98, 377 (2010).

7. H. Wang, J. K. Actor, J. Indrigo, M. Olsen, and A. Dasgupta, Clin. Chim. Acta. 327, 123 (2003).

8. M. R. -M. I. Imaz, W. J. Saletra, L. Garcia-Fernaındez, F. Garcia, D. Ruiz-Molina, J. Hernando, V. Puntes, and D. Maspoch, Chem. Commun. 46, 4737 (2010).

9. C. R. Martin, and P. Kohli, Nat. Rev. Drug Discovery 2, 29 (2003).

10. P. K. Jain, X. Huang, I. H. El-Sayed, and M. A. El-Sayed, Acc. Chem. Res. 41, 1578 (2008).

11. K. Leonard, B. Ahmmad, H. Okamura, and J. Kurawaki, Colloids Surf. B. 82, 391 (2011)

12. (a) Y. Su, Z. Fu, J. Zhang, W. Wang, H. Wang, Y. Wang, and Q. Zhang, Powder Technol. 184, 114 (2008); (b) H. W. Wen, W. C. Li, R. J. Chung, S. Y. Yin, T. H. Chou, P. C. Hsieh, P. H. Wang, and I. Lin, J. Nanosci. Nanotechnol. 7, 4108 (2009).

13. (a) F. Xiong, H. Chen, X. Chang, Y. Yang, H. Xu, and X. Yang, IEEE 10, 4966 (2006); (b) X. Song, L. Zang, and S. Hu. Vaccine 27, 2306 (2009).

14. (a) M. Murakami, H. Cabral, Y. Matsumoto, S. Wu, M. R. Kano, T. Yamori, N. Nishiyama, and K. Kataoka, Sci. Trans. Med. 3, 642 (2011); (b) Z. Zhang, W. Cao, H. Jin, J. F. Lovell, M. Yang, L. Ding, J. Chen, I. Corbin, Q. Luo, and G. Zheng, Angew. Chem. Int. Ed. 48, 9171 (2009).

15. Y. Su, Z. Y. Fu, W. M. Wang, H. Wang, Y. C. Wang, J. Y. Zhang, and P. Ma, Key. Eng. Mater. 330, 215 (2007).

16. R. Li, W. Dong, H. He, H. Yan, X. Jiang, and J. Gong, Cry. Res. Technol. 4, 377 (2012).

17. G. Lu, Q. Zhou, S. Sun, K. S. Leung, H. Zhang, and Z. Zhao, J. Mol. Struct. 883, 91 (2008).

18. D. Liu, Y. G. Li, H. Xu, S. Q. Sun, and Z. T. Wang, J. Mol. Struct. 883, 228 (2008).

19. B. S. Sun, L. J. Gu, Z. M. Fang, C. Wang, Z. Wang, M. R. Lee, Z. Li, J. J. Li, and C. K. Sung, J. Pharm. Biomed. Anal. 50, 15 (2009).

20. H. Y. Kim and K. Kim, J. Agric. Food Chem. 55, 2816 (2007)

21. (a) J. J. Yin, F. Lao, P. P. Fu, W. G. Wamer, Y. Zhao, P. C. Wang, Y. Qiu, B. Sun, G. Xing, and J. Dong, Biomaterials 30, 611 (2009); (b) Y. Chang, S. T. Yang, J. H. Liu, E. Dong, Y. Wang, A. Cao, Y. Liu, and H. Wang, Toxicol. Lett. 200, 201 (2010).

22. S. Sun, L. W. Qi, G. J. Du, S. R. Mehendale, C. Z. Wang, and C. S. Yuan, Food Chem. 125, 1299 (2011).

Received: 08 March 2012. Accepted: 22 April 2012. 